\title{
Synthesis and catalysis of tungsten oxide in hexagonal mesoporous silicas (W-HMS)
}

\author{
Iou-Sheng Ke, Shiuh-Tzung Liu* \\ Department of Chemistry, National Taiwan University, 1, Sec. 4, Roosevelt Road, Taipei 106, Taiwan, ROC \\ Received 11 July 2006; received in revised form 26 September 2006; accepted 5 October 2006 \\ Available online 15 November 2006
}

\begin{abstract}
Hexagonal mesoporous silicas containing tungsten complexes have been synthesized through the condensation of tetraethoxysilane templated by an amphiphilic diblock copolymers modified with tungsten isocyanide complexes under acidic conditions. Upon calcination, the tungsten complex was transformed into its oxide, which was deposited inside the channels. This material is illustrated to be a good catalyst on the allylic oxidation of cyclohexene in the presence of hydrogen peroxide under mild conditions. In addition, this catalyst could be easily recovered after the reaction and re-used without any significant loss of its activity.
\end{abstract}

(C) 2006 Elsevier B.V. All rights reserved.

Keywords: Silicas; Tungsten; Oxidation; Cyclohexene

\section{Introduction}

Tungsten oxides and related mixed oxides play a relevant role in oxygen transfer reaction particularly as catalysts in oxidation of various organic substrates $[1,2]$. In recent years, interest in the development of environmentally benign synthesis has induced the immobilization of metal oxide onto solid supports to provide heterogeneous catalysts with high activity and selectivity [3-14]. Traditional physisorbed heterogeneous catalysts were prepared by adsorption or ionpair formation of one or more components onto the surface of solid carrier. However, the efficiency of this kind of heterogenization with channel-like materials such as porous silica remains as a challenge. Another approach is the addition of sodium tungstate during the gelation process to ensure the metal uniformly dispersed into the lattice of porous silica [14]. The idea of this work is to synthesize metal bound copolymers, which were used as templates to construct mesoporous silica. Upon removal of organic residue, the metal species could be embedded inside the channels. Furthermore, this material can be used as a catalyst for the oxidation of cyclohexene.

\footnotetext{
* Corresponding author. Tel.: +886 23366 1661; fax: +886223636359. E-mail address: stliu@ntu.edu.tw (S.-T. Liu).
}

\section{Experimental}

\subsection{General information}

All reaction steps for polymerization were performed under a dry nitrogen atmosphere. Dichoromethane was dried with $\mathrm{CaH}_{2}$ and distilled under nitrogen. Poly(ethylene glycol) methyl ether $\left[\mathrm{CH}_{3}\left(\mathrm{OCH}_{2} \mathrm{CH}_{2}\right)_{n} \mathrm{OH}\right]$ with an average molecular weight 2000 were obtained from Acrôs and used without further purification. Tetraethoxysilane (TEOS), other chemicals and solvents were of analytical grade and were used as received.

Nuclear magnetic resonance spectra were recorded in $\mathrm{CDCl}_{3}$ on either a Bruker AC-E 200 or AM-300 spectrometer. Infrared spectra were measured on a Nicolet Magna-IR 550 spectrometer (Series-II) as $\mathrm{KBr}$ pallets. Gel permeation chromatography (GPC) data were obtained from a Waters Model 590 liquid chromatograph installed with a Lab Allience RI 2000 detector using THF as eluant (at the rate $1 \mathrm{~mL} / \mathrm{min}$ ) at $40{ }^{\circ} \mathrm{C}$ and polystyrene calibration curve for analyses.

\subsection{Preparation of macro-initiator 2}

A mixture of tosylate $1(10 \mathrm{~g}, 11 \mathrm{mmol})$ and sodium azide $(2.86 \mathrm{~g}, 44 \mathrm{~mol})$ in a $250 \mathrm{~mL}$ flask was added with acetone $(150 \mathrm{~mL})$. The resulting mixture was heated to reflux for 
$24 \mathrm{~h}$. Upon filtration off the salt, the azido compound was obtained $(8.1 \mathrm{~g}, 95 \%)$ : ${ }^{1} \mathrm{H}$ NMR $\left(300 \mathrm{MHz}, \mathrm{CDCl}_{3}\right) \delta 3.61(\mathrm{~s}$, $\left.64 \mathrm{H},-\mathrm{OCH}_{2} \mathrm{CH}_{2} \mathrm{O}-\right), 3.52\left(\mathrm{t}, J=5.1 \mathrm{~Hz}, 2 \mathrm{H},-\mathrm{OCH}_{2} \mathrm{CH}_{2} \mathrm{~N}_{3}\right.$ ), $3.38\left(\mathrm{t}, J=5.2 \mathrm{~Hz}, 2 \mathrm{H},-\mathrm{OCH}_{2} \mathrm{CH}_{2} \mathrm{~N}_{3}\right), 3.35\left(\mathrm{~s}, 3 \mathrm{H},-\mathrm{OCH}_{3}\right)$.

The azido compound ( $8 \mathrm{~g}, 10.4 \mathrm{mmol})$ in a degassed flask was added anhydrous THF $(50 \mathrm{~mL})$. Triphenylphosphine (10.2 $\mathrm{g}, 39 \mathrm{mmol})$ in THF $(30 \mathrm{~mL})$ was slowly added to the above solution with stirring for $12 \mathrm{~h}$. Water was then added to convert the phosphimine into amino functionality. The reaction mixture was washed with toluene $(50 \mathrm{~mL} \times 3)$ and the aqueous portion was collected. Upon concentration, the desired amino compound was obtained as viscous oils $(9.05 \mathrm{~g}, 93 \%):{ }^{1} \mathrm{H}$ NMR $\left(300 \mathrm{MHz}, \mathrm{CDCl}_{3}\right) \delta 3.61\left(\mathrm{~s}, 64 \mathrm{H},-\mathrm{OCH}_{2} \mathrm{CH}_{2} \mathrm{O}-\right), 3.48(\mathrm{t}$, $\left.J=5.0 \mathrm{~Hz}, 2 \mathrm{H},-\mathrm{OCH}_{2} \mathrm{CH}_{2} \mathrm{NH}_{2}\right), 3.35\left(\mathrm{~s}, 3 \mathrm{H},-\mathrm{OCH}_{3}\right), 2.83(\mathrm{t}$, $J=5.2 \mathrm{~Hz}, 2 \mathrm{H},-\mathrm{OCH}_{2} \mathrm{CH}_{2} \mathrm{NH}_{2}$ ).

The amine compound $(9 \mathrm{~g}, 11.7 \mathrm{mmol})$ from the last step was added to a solution of triethylamine $(3.2 \mathrm{~mL}$, $23.4 \mathrm{mmol})$ in $\mathrm{CH}_{2} \mathrm{Cl}_{2}(50 \mathrm{~mL})$ with stirring. 2-Bromoisobutyryl bromide $(2.9 \mathrm{~mL}, 23.4 \mathrm{mmol})$ was added drop wise at ice-cooled temperature. After the addition, the resulting mixture was stirred at ambient temperature for $24 \mathrm{~h}$. A small amount of water was added to quench the acyl bromide and the salts was filtered off. The residue was extracted with ether $(50 \mathrm{~mL} \times 3)$. Upon concentration, the residue was dissolved in dichloromethane. The desired macro-initiator 2 was precipitated by the addition of ice-cooled ether: ${ }^{1} \mathrm{H}$ NMR $\left(300 \mathrm{MHz}, \mathrm{CDCl}_{3}\right) 3.61\left(\mathrm{~s}, 64 \mathrm{H},-\mathrm{OCH}_{2} \mathrm{CH}_{2} \mathrm{O}-\right), 3.52(\mathrm{t}$, $\left.J=5.1 \mathrm{~Hz}, 2 \mathrm{H},-\mathrm{OCH}_{2} \mathrm{CH}_{2} \mathrm{~N}_{3}\right), 3.38\left(\mathrm{t}, 2 \mathrm{H},-\mathrm{OCH}_{2} \mathrm{CH}_{2} \mathrm{~N}_{3}\right)$, $3.35\left(\mathrm{~s}, 3 \mathrm{H},-\mathrm{OCH}_{3}\right), 1.92\left(\mathrm{~s}, 6 \mathrm{H},-\mathrm{CH}_{3}\right)$. Anal. Calcd for $\mathrm{C}_{39} \mathrm{H}_{78} \mathrm{BrNO}_{18}$ : C, 50.43; H, 8.46; N, 1.51. Found: C, 50.01; $\mathrm{H}, 7.99 ; \mathrm{N}, 1.22$.

\subsection{Preparation of diblock copolymers}

A mixture of macro-initiator 2 (1 mmol), CuBr $(28.6 \mathrm{mg}$, $0.2 \mathrm{mmol}$ ) in $50 \mathrm{~mL}$ flask was capped with septum and was degassed. Methyl acrylate $(7.2 \mathrm{~mL}, 80 \mathrm{mmol})$ was syringed into the flask under nitrogen atmosphere. The flask was immersed into a water-bath at $30{ }^{\circ} \mathrm{C}$. [ $\left.\left(\mathrm{Me}_{2} \mathrm{NCH}_{2} \mathrm{CH}_{2}\right)_{3} \mathrm{~N}\right]$ (56 $\mu \mathrm{L}, 0.2 \mathrm{mmol}$ ) was then added [15]. After stirring at $30{ }^{\circ} \mathrm{C}$ for $30 \mathrm{~min}$, the reaction mixture was diluted with THF. The reaction mixture was filtered through silica gel to remove the catalyst. Upon concentration and re-precipitation in ether/ methanol, the obtained copolymer was dried under vacuum overnight. The desired copolymer EO-MA was obtained in a white solid form $(8.2 \mathrm{~g}):{ }^{1} \mathrm{H} \mathrm{NMR}\left(400 \mathrm{MHz}, \mathrm{CDCl}_{3}\right) \delta 3.70-$ $3.60\left(\mathrm{br}, 168 \mathrm{H},-\mathrm{COOCH}_{3}\right), 3.62\left(\mathrm{~s}, 178 \mathrm{H},-\mathrm{OCH}_{2} \mathrm{CH}_{2} \mathrm{O}-\right)$, $3.40\left(\mathrm{~s}, 3 \mathrm{H},-\mathrm{OCH}_{3}\right), 2.40-2.10(\mathrm{br}, 56 \mathrm{H}), 2.00-1.30(\mathrm{br}, 112 \mathrm{H})$, $1.14\left(\mathrm{~s}, 3 \mathrm{H},-\mathrm{C}\left(\mathrm{CH}_{3}\right)_{2}\right), 1.12\left(\mathrm{~s}, 3 \mathrm{H},-\mathrm{C}\left(\mathrm{CH}_{3}\right)_{2}\right) . M_{\mathrm{N}}=7600$, $\mathrm{PDI}=1.17$. By the NMR integration and GPC analysis, the diblock copolymer contains the acrylate length in an average of 63 units.

\subsection{Preparation of modified diblock copolymers}

In a $10 \mathrm{~mL}$ round bottom flask was placed with diblock copolymer $(2 \mathrm{~g})$ and $\mathrm{NH}_{2} \mathrm{CH}_{2} \mathrm{CH}_{2} \mathrm{CH}_{2} \mathrm{~N}_{3}(5 \mathrm{~mL})$. The mixture was heated at $100{ }^{\circ} \mathrm{C}$ for $9 \mathrm{~h}$ and the excess of amine was removed by vacuum distillation. The residue was dissolved in $\mathrm{CH}_{2} \mathrm{Cl}_{2}(2 \mathrm{~mL})$. The desired copolymer was precipitated by addition of hexane. Decant the solvents and wash the white solid with hexane $(10 \mathrm{~mL} \times 2)$. The white solids were collected and dried under vacuum overnight. ${ }^{1} \mathrm{H}$ NMR $(400 \mathrm{MHz}$, $\left.\mathrm{CDCl}_{3}\right) \delta$ 3.70-3.60(br, $-\mathrm{COOCH}_{3}$ ), 3.62(s, $-\mathrm{OCH}_{2} \mathrm{CH}_{2} \mathrm{O}-$ ), $3.40\left(\mathrm{~s}, 3 \mathrm{H},-\mathrm{OCH}_{3}\right), 3.33\left(\mathrm{br}, 40 \mathrm{H},-\mathrm{CH}_{2} \mathrm{~N}_{3}\right), 2.88(\mathrm{br}, 40 \mathrm{H}$, $\left.-\mathrm{CH}_{2} \mathrm{NH}_{2}\right), 2.40-2.10(\mathrm{br}, 56 \mathrm{H}), 2.00-1.30(\mathrm{br}, 112 \mathrm{H})$, $1.63\left(\mathrm{br}, 40 \mathrm{H},-\mathrm{CH}_{2} \mathrm{CH}_{2} \mathrm{NH}_{2}\right), 1.14\left(\mathrm{~s}, 3 \mathrm{H},-\mathrm{COC}\left(\mathrm{CH}_{3}\right)_{2}\right)$, 1.12(s, 3H, $\left.-\mathrm{COC}\left(\mathrm{CH}_{3}\right)_{2}\right)$; IR $\left(\mathrm{KBr}, \mathrm{cm}^{-1}\right): 3423\left(\mathrm{br}, \mathrm{v}_{\mathrm{N}-\mathrm{H}}\right)$, $2100\left(\mathrm{~s}, v_{\mathrm{N}_{3}}\right), 1746\left(v_{\mathrm{C}=\mathrm{O}}\right), 1640\left(v_{\mathrm{C}=\mathrm{O}}\right)$. Based on ${ }^{1} \mathrm{H}$ NMR integration, the amide units on the polymer were estimated in the average of 20 per polymer chain.

\subsection{Preparation of tungsten containing diblock copolymers}

Copolymer EO-MA-N (2.0 g) in THF (10 mL) was dried under vacuum and flashed with nitrogen gas. Triphenylphosphine $(1.17 \mathrm{~g}, 4.4 \mathrm{mmol})$ in THF $(3 \mathrm{~mL})$ was added to the above solution at room temperature with stirring [16]. The mixture was stirred for overnight. $\mathrm{W}(\mathrm{CO})_{6}(1.54 \mathrm{~g}, 4.4 \mathrm{mmol})$ in THF $(10 \mathrm{~mL})$ was then added. The resulting mixture was stirred at room temperature for another $20 \mathrm{~h}$. After removal of THF, the residue was dissolved in $\mathrm{CH}_{2} \mathrm{Cl}_{2}$ and the desired polymer EO-MA-W (3.2 g) was obtained by precipitation with the addition of hexane. ${ }^{1} \mathrm{H}$ NMR $\left(400 \mathrm{MHz}, \mathrm{CDCl}_{3}\right) \delta$ 3.70-3.60(br, $-\mathrm{COOCH}_{3}$ ), 3.62(s, $-\mathrm{OCH}_{2} \mathrm{CH}_{2} \mathrm{O}-$ ), 3.40(s, 3H, $\left.-\mathrm{OCH}_{3}\right), 3.33\left(\mathrm{br},(2 \mathrm{Z}) \mathrm{H},-\mathrm{CH}_{2} \mathrm{NC}\right), 2.88\left(\mathrm{br},-\mathrm{CH}_{2} \mathrm{NH}_{2}\right), 2.40-$ 2.10(br), 2.00-1.30(br), 1.63(br, (2Z)H, $-\mathrm{CH}_{2} \mathrm{CH}_{2} \mathrm{NH}_{2}$ ), $1.14\left(\mathrm{~s}, 3 \mathrm{H},-\mathrm{COC}\left(\mathrm{CH}_{3}\right)_{2}\right), 1.12\left(\mathrm{~s}, 3 \mathrm{H},-\mathrm{COC}\left(\mathrm{CH}_{3}\right)_{2}\right)$; IR (KBr) 3423, 2177, 2060, 1958, 1746, 1673, $1560 \mathrm{~cm}^{-1}$.

\subsection{Preparation of mesoporous silicas modified with metal complexes}

The silica mesostructural composites via $(\mathrm{EO})_{45}(\mathrm{MA})_{56}-\mathrm{W}$ templates were synthesized in acidic media as that for SBA-15 silicas [17]. Copolymer and $37 \% \mathrm{HCl}$ were dissolved in water with stirring. To this solution was added tetrethoxysilane (TEOS) at $20^{\circ} \mathrm{C}$. The as-synthesized mesoporous silica products were obtained after 1 day agitation at $25-50{ }^{\circ} \mathrm{C}$. The final gel composition (in gram) is: (0.5 g) EO-MAW:(25.0 g) $\mathrm{H}_{2} \mathrm{O}:(6.0 \mathrm{~g}) 37 \% \mathrm{HCl}:(1.5 \mathrm{~g})$ TEOS. In order to increase the orderness and stability, the dried mesoporous silicas in $50.0 \mathrm{~g}$ water were hydrothermally treated at $100{ }^{\circ} \mathrm{C}$ for $24 \mathrm{~h}$. The organic templates were removed by calcinations at $560{ }^{\circ} \mathrm{C}$ in air for $6 \mathrm{~h}$ under air, which allowed the tungsten complex to form the metal oxide.

\subsection{Characterization of mesoporous silicas}

The powder X-ray diffraction patterns (XRD) were taken on Wiggler-A beamline $(\lambda=0.1326 \mathrm{~nm})$ of Taiwan National Synchrotron Radiation Research Center, Hsin-Chu, Taiwan. The TEM mesostructural images of mesoporous silicas were 
recorded on Hitachi S-7100 transmission electron microscope (TEM) with an operating voltage of $75 \mathrm{keV}$. The $\mathrm{N}_{2}$ adsorption-desorption isotherms (S) were obtained at $77 \mathrm{~K}$ on a Micromeritics ASAP 2010 apparatus, and the pore size distribution was calculated from the adsorption isotherms using the Barrett-Joyner-Halenda (BJH) method.

\subsection{Catalysis}

A mixture of substrate $(5 \mathrm{mmol}), \mathrm{H}_{2} \mathrm{O}_{2}(37 \%, 10 \mathrm{mmol})$, acetonitrile $(1 \mathrm{~mL})$ and the synthesized tungsten oxide-silica (5 mg) was placed in a $20 \mathrm{~mL}$ flask. The solution was stirred at room temperature. Upon standing for $1 \mathrm{~h}$, the organic layer (product) was separated from the reaction mixture, and the aqueous layer was extracted with dichloromethane $(2 \mathrm{~mL})$. The combined organic portions was dried and concentrated. Product analysis was performed by GC and ${ }^{1} \mathrm{H}$ NMR spectroscopic methods.

\section{Results and discussion}

\subsection{Synthesis of amphiphilic diblock copolymers}

Starting with the methyl-capped polyethylene oxide $\mathrm{Me}\left(\mathrm{OCH}_{2} \mathrm{CH}_{2}\right)_{45} \mathrm{OH} \mathrm{1}$, the hydroxy function was transferred into an amine function, which was subsequently reacted with 2bromoisobutyric chloride to provide the macro-initiator poly(ethylene oxide)-2-bromoisobutyrate 2 (Scheme 1). The amide linkage of this macro-initiator is necessary for the latter functional group manipulations. Compound $\mathbf{2}$ was subjected to connect the hydrophobic poly(methyl acrylate) by the atom transfer radical polymerization method [15]. Typically, reaction of macro-initiator $(0.93 \mathrm{mmol})$ and methyl acrylate [MA] $(55 \mathrm{mmol})$ at $30{ }^{\circ} \mathrm{C}$ for $30 \mathrm{~min}$ resulted in the formation of the desired EO-MA in $\mathrm{M}_{\mathrm{N}}=7600(\mathrm{PDI}=1.17)$. Based on the GPC and ${ }^{1} \mathrm{H}$ NMR integration, the polymerization degree of MA is in an average of 63 units.

The ester groups of copolymer chain were partially replaced with 3-aminopropyl azide to yield the corresponding amide compound. The advantage of using this amine-azide is its relatively low boiling point $\left(56-58{ }^{\circ} \mathrm{C} / 16\right.$ Torr $)$. Thus, the excess of the amine-azide compound can be easily removed from the copolymer. The composition of the resulting copolymer (EO-MA-N), determined by ${ }^{1} \mathrm{H}$ NMR integration, included $0.3 \mathrm{~mol}$ fraction of the azido group. Infrared absorptions at 2100, 1746 and $1640 \mathrm{~cm}^{-1}$ is characteristic for stretching of $-\mathrm{N}_{3}, \mathrm{C}=\mathrm{O}$ of ester and $\mathrm{C}=\mathrm{O}$ of amide, respectively, which are further confirmed the functionalities of the copolymer. Under anhydrous conditions, the copolymer EO-MA-N was treated with triphenylphosphine to generate the iminophosphorane functionality [16], which subsequently reacted with $\mathrm{W}(\mathrm{CO})_{6}$ to give the corresponding isocyanide complex EO-MA-W (Scheme 1). The presence of tungsten carbonyl complexes in copolymers was confirmed by IR spectrum. Two absorption bands were observed at 2060 and $1958 \mathrm{~cm}^{-1}$, which were consistent with the characteristic CO stretching of the tungsten pentacarbonyl moiety. The other peak at $2177 \mathrm{~cm}^{-1}$ was the stretching frequency for the coordinated isocyanide.

\subsection{Preparation and characterization of mesoporous silicas}

The synthesis of ordered hexagonal mesoporous silica (denoted as $\mathrm{Si}_{\text {EO-MA }}, \mathrm{Si}_{\text {EO-MA-N }}$ and $\mathrm{Si}_{\text {EO-MA-W) }}$ under acidic conditions was achieved by using the nonionic diblock copolymers EO-MA, EO-MA-N and EO-MA-W as templates, respectively. In a typical synthesis, $2.0 \mathrm{~g}$ of copolymer and $6.0 \mathrm{~g}$ of $37 \% \mathrm{HCl}$ was dissolved in $25 \mathrm{~g}$ water with stirring at $\mathrm{rt}$. To this solution was added tetraethoxysilane $(1.5 \mathrm{~g})$, and then the mixture was stirred for $24 \mathrm{~h}$ at the same temperature. Subsequently, the mixture was transferred into Teflon-lined autoclave and heated at $100{ }^{\circ} \mathrm{C}$ for another $24 \mathrm{~h}$ under static conditions. The solid products were collected by filtration, washed thoroughly with water, and air-dried at room temperature. This solid was calcined at $560{ }^{\circ} \mathrm{C}$ in order to remove the copolymers and convert the tungsten complex into tungsten oxide in case of $\mathrm{Si}_{\mathbf{E O} \text {-MA-W. }}$
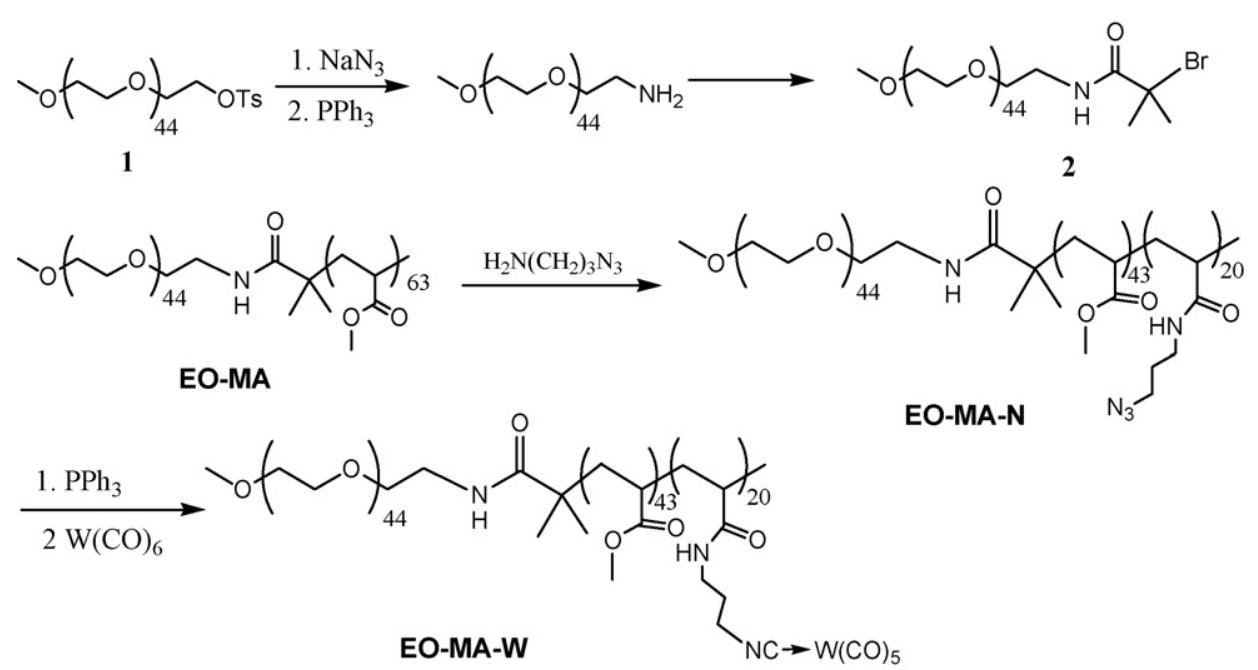

Scheme 1. The synthetic approach for the metal containing diblock copolymer. 


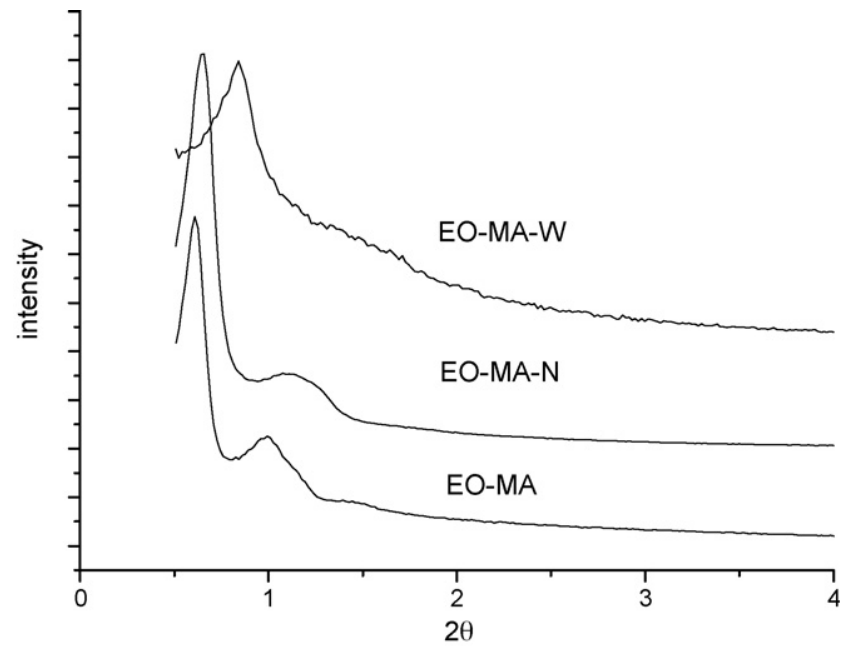

Fig. 1. XRD patterns of mesoporous silicas obtained via EO-MA-X template.

Fig. 1 shows X-ray diffraction patterns of samples prepared with the modified EO-MA copolymers. For the use of EO-MA and modified copolymers as the templates, XRD pattern typical of hexagonal mesoporous silica (HMS) were obtained. However, a decrease of $d_{100}$ spacing is observed for the sample synthesized with the use of EO-MA-W template, the intensities of the peaks decrease and the higher order reflection (2 00 ) has diminished. The presence of orgnometallic groups in the copolymer appears to disturb the self-assembly of amiphilic copolymer aggregates during the co-condensation.

Physical properties for the calcined $\mathrm{Si}_{\text {EO-MA-X }}$ samples are summarized in Table 1. Notable is the different nature of the sample $\mathrm{Si}_{\text {EO-MA-w }}$ from others. Transmission electron microscopy (TEM) images further confirm the well-order hexagonal array of mesoporous channels in the $\mathrm{Si}_{\mathbf{E O} \text {-MA }}$ material (Fig. 2a). The pore diameter shown in the TEM image is around $13 \mathrm{~nm}$, in good agreement with the value determined from the $\mathrm{N}_{2}$ adsorption measurement. On the other hand, the $\mathrm{Si}_{\text {EO-MA-w }}$ (W-HMS) sample displayed pores in relatively ordered orientation, but smaller size (Fig. 2b). It is worthy to mention that no agglomeration of tungsten oxide could be observed on the surface of mesoporous silicas, suggesting a well-dispersed manner of the oxide.

From the ICP mass determination, the quantity of tungsten embedded in the silica was found to be $43 \mathrm{mg} \mathrm{W} / \mathrm{g}$ silica, which
Table 1

Physical property of porous silicas

\begin{tabular}{llll}
\hline Sample & $\begin{array}{l}\text { Surface area } \\
\left(\mathrm{m}^{2} / \mathrm{g}\right)\end{array}$ & $\begin{array}{l}\text { Pore size } \\
(\mathrm{nm})\end{array}$ & $\begin{array}{l}\text { Pore volume } \\
\left(\mathrm{cm}^{3} / \mathrm{g}\right)\end{array}$ \\
\hline $\mathrm{Si}_{\text {EO-MA }}$ & 628 & 13.2 & 0.61 \\
$\mathrm{Si}_{\text {EO-MA-N }}$ & 606 & 12.7 & 0.61 \\
$\mathrm{Si}_{\text {EO-MA-W }}$ & 474 & 9.9 & 0.66 \\
\hline
\end{tabular}

is in agreement of the amount used for the copolymer complexes. This is, the quantity of tungsten remains during the synthetic preparation. For the X-ray photoelectron spectroscopy scanning of the W-HMS sample, the peaks corresponding to $4 \mathrm{f}_{7 / 2}$ and $4 \mathrm{f}_{5 / 2}$ were observed at 35.6 and $37.8 \mathrm{eV}$, respectively, which are consistent with those of the tungsten(VI) oxide.

\subsection{Catalytic oxidation of olefins}

Oxidation of cyclohexene with hydrogen peroxide over WHMS was investigated. In a typical run, cyclohexene and $\mathrm{H}_{2} \mathrm{O}_{2}$ in a ratio of 1:2 were added to a mixture of acetonitrile and water solution, followed by the addition of W-HMS. Instead of oxidative cleavage, it was found that cyclohexene was smoothly converted into 2-cyclohexenone and 2-cyclohexenol. Running the reaction with the use of Mesoporous silicas $\mathrm{Si}_{\mathbf{E O}-\mathbf{M A}}$ as the catalyst did not give any oxidation product, indicating that the tungsten(VI) species were participated in the catalysis. On the other hand, the use of catalyst prepared by loading of $\mathrm{Na}_{2} \mathrm{WO}_{4}$ into the mesoporous silica $\mathrm{Si}_{\mathbf{E O}}$-MA did not provide cyclohexanol under the similar reaction conditions, but the cyclohexene oxide products instead. This observation is quite similar to that of the reported work [10], indicating that the catalyst developed in this work has a distinctive activity. As indicated in Table 1, when the mole ratio of cyclohexanone and $\mathrm{H}_{2} \mathrm{O}_{2}$ is $1: 2$, amount of catalyst is $3 \mathrm{mg}$, reaction time is $5 \mathrm{~h}$, the reaction condition was optimum and the yields of 2-cyclohexenol and 2cyclohexenone are up to $77 \%$ and $8 \%$, respectively (entry 1). It is noticed that cyclooctene or 1-octene does not undergo either cleavage or allylic oxidation under the reaction temperature at $40{ }^{\circ} \mathrm{C}$. In fact, the use of a mixture of cyclohexene and cyclooctene as substrates only provided the oxidation products from cyclohexene, showing the substrate (a)

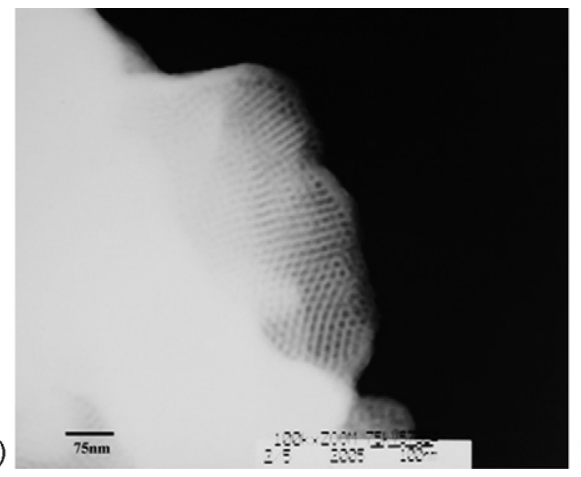

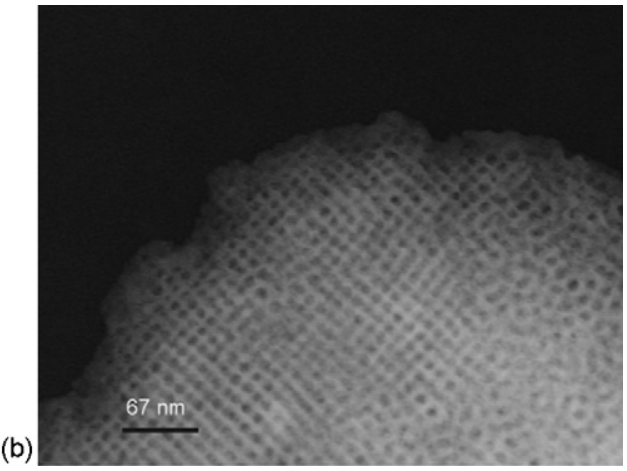

Fig. 2. TEM micrographs of silicas (a) $\mathrm{Si}_{\mathbf{E O}-\mathbf{M A}}$ and (b) $\mathrm{Si}_{\mathbf{E O}-\mathbf{M A}-\mathbf{W} \text {. }}$ 
Table 2

Oxidation of olefins catalyzed by W-HMS

\begin{tabular}{clcllcl}
\hline Entry & Substrate & Time $(\mathrm{h})$ & $t\left({ }^{\circ} \mathrm{C}\right)$ & Oxidant & Conversion $(\%)$ & Product (yield in percent) \\
\hline 1 & Cyclohexene & 5 & 40 & $\mathrm{H}_{2} \mathrm{O}_{2}$ & 100 & 2-Cyclohexenol (77), 2-cyclohexenone (8) \\
$2^{\mathrm{a}}$ & Cyclohexene & 12 & 40 & $\mathrm{H}_{2} \mathrm{O}_{2}$ & - & - 2-Cyclohexenol (55), 2-cyclohexenone (5) \\
3 & Cyclohexene & 3 & 40 & $\mathrm{H}_{2} \mathrm{O}_{2}$ & 68 & 2-Cyclohexenol (35), 2-cyclohexenone (5) \\
4 & Cyclohexene & 5 & 40 & $\mathrm{H}_{2} \mathrm{O}_{2}{ }^{\mathrm{b}}$ & 50 & 2-Cyclohexenol (35), 2-cyclohexenone (5) \\
5 & Cyclohexene & 5 & $\mathrm{rt}$ & $\mathrm{H}_{2} \mathrm{O}_{2}$ & 30 & Trace \\
6 & Cyclohexene & 12 & 40 & $\mathrm{NaIO}_{4}$ & $<5$ & Trace \\
7 & Cyclohexene & 12 & 40 & $\mathrm{NaOCl}$ & $<5$ & - \\
8 & Cyclooctene & 6 & 40 & $\mathrm{H}_{2} \mathrm{O}_{2}$ & - & - \\
9 & 1-Octene & 60 & $\mathrm{H}_{2} \mathrm{O}_{2}$ & - & - \\
10 & Cyclohexene + cyclooctene & 6 & 40 & $\mathrm{H}_{2} \mathrm{O}_{2}$ & - & 2-Cyclohexenol, 2-cyclohexenone \\
11 & 1-Phenylethanol & 12 & 40 & $\mathrm{H}_{2} \mathrm{O}_{2}$ & $<10$ & Acetophenone $(\sim 5)$
\end{tabular}

Reaction conditions: substrate $(3 \mathrm{mmol})$, oxidant $(10 \mathrm{mmol})$, catalyst $(3 \mathrm{mg})$ in water $(10 \mathrm{~mL}) / \mathrm{CH}_{3} \mathrm{CN}(1 \mathrm{~mL})$.

${ }^{\text {a }}$ Mesoporous silicas $\mathrm{Si}_{\mathbf{E O} \text {-MA }}$ as the catalyst.

b 5 mmol.

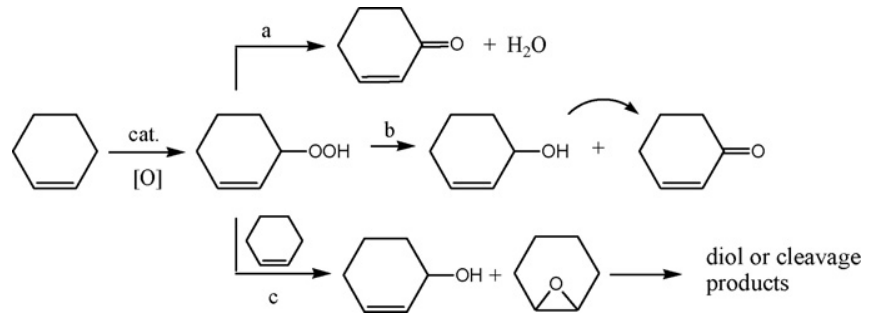

Scheme 2. Oxidation pathway of cyclohexene.

selectivity of this catalyst (entry 10 , Table 2 ). We found that the use of other oxidants such as periodate or hypochlorite on this oxidation gave poor results.

It is known that the oxidation of cyclohexene initially forms 2-cyclohexene-1-hydroperoxide as the primary intermediate, which then undergoes various pathways leading to the epoxide followed by the cleavage or allyic oxidation products (Scheme 2) [18]. The formation of hydroperoxide species is the step in controlling the conversion of cyclohexene. On the other hand,

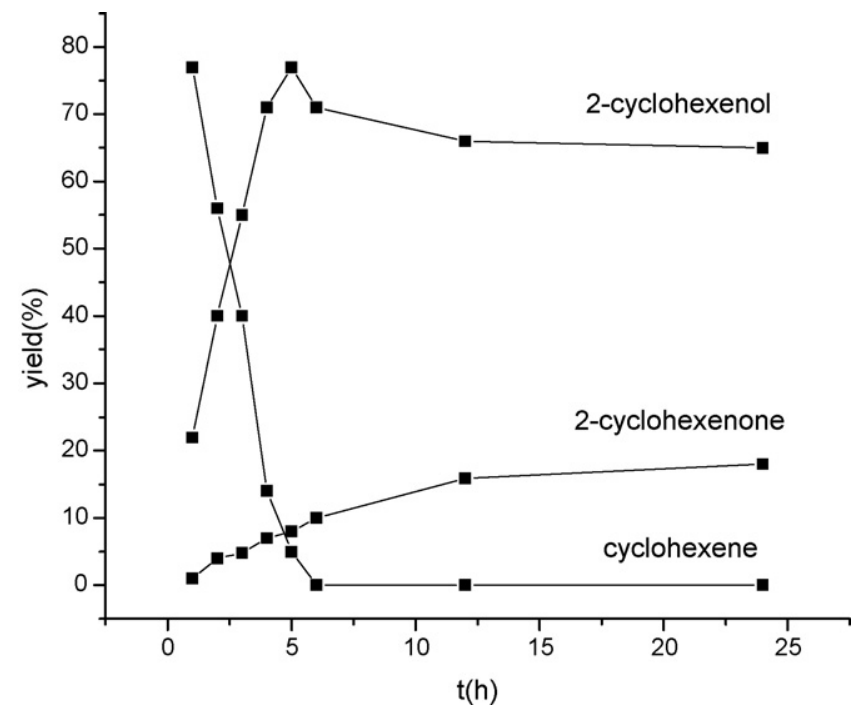

Fig. 3. The effect of reaction time on cyclohexene conversion and selectivities of the products. Conditions: catalyst $2.4 \mathrm{mg}$, cyclohexene $2.0 \mathrm{~mL}$ (19.7 mmol) in $\mathrm{H}_{2} \mathrm{O} / \mathrm{CH}_{3} \mathrm{CN}(9: 1,10 \mathrm{~mL})$ at $40{ }^{\circ} \mathrm{C}$. selectivity of the product distribution is governed by the rate ratio of steps a-c. Apparently, the decomposition of hydroperoxide species leading to 2-cyclohexenol catalyzed by the W-HMS developed in this work is much faster than those of the other two processes, which makes the catalyst having good selectivity.

As shown in Fig. 3, the complete conversion of cyclohexene was accomplished within $6 \mathrm{~h}$, but with prolonged reaction time, the ratio of ketone/alcohol increased, indicating that the catalytic system assists the further oxidation of alcohol product into the ketone. In fact, the catalyst is able to carry out the oxidation of benzylic alcohol into the corresponding ketone slowly (entry 12, Table 2).

Since the by-product is water from this catalytic reaction, the re-use of catalyst was quite simple. After the catalysis, the organic products were separated by extraction from the water layer. The aqueous portion with the catalyst precipitated at the bottom of the reactor was ready for further use, i.e. the recycled catalyst does not require any pre-treatment for the next run. In order to investigate the stability and duration of active $\mathrm{W}$-species in the catalyst, the leaching of tungsten species into the product mixture was determined after five reaction cycles. From the ICP mass analysis, no detectable leaching of tungsten was found, suggesting that the tungsten oxide species were well immobilized inside the silica-based channels. Results of the oxidation of cyclohexene over this catalyst with different reaction cycles are listed in Table 3. It was also

Table 3

Recycle use of catalyst on the oxidation of cyclohexene ${ }^{a}$

\begin{tabular}{lll}
\hline Run & Yields $^{\text {b }}$ & \\
\cline { 2 - 3 } & 2-Cyclohexenol (\%) & 2-Cyclohexenone (\%) \\
\hline 1 & 77 & 8 \\
2 & 70 & 7 \\
3 & 72 & 8 \\
4 & 68 & 5 \\
5 & 70 & 6
\end{tabular}

${ }^{\mathrm{a}}$ Reaction conditions: $5 \mathrm{mmol}$ cyclohexene and $10 \mathrm{mmol} \mathrm{H}_{2} \mathrm{O}_{2}$ for each run. ${ }^{\mathrm{b}}$ GC yield. 
noticed that the selectivity did not show a discrepancy along with the repeated cycles.

\section{Conclusions}

This work has developed a new synthetic approach to prepare tungsten oxide in the porous silicas. This mesoporous solid supported tungsten oxide (W-HMS) proves to be an active and reusable catalyst for cyclohexene oxidation with the presence of hydrogen peroxide as an oxidant; high conversion and selectivity can be achieved under mild reaction conditions. As for the nature of this tungsten species is currently under investigation.

\section{Acknowledgment}

This work was supported by the National Science Council, Taiwan, ROC for the financial support (NSC94-2113-M002035).

\section{Appendix A. Supplementary data}

Supplementary data associated with this article can be found, in the online version, at doi:10.1016/j.apcata.2006.10.007.

\section{References}

[1] J.-E. Bäckvall (Ed.), Modern Oxidation Methods, Wiley-VCH, Weinheim, 2004.

[2] F.E. Kuehn, R.W. Fischer, W.A. Herrmann, T. Weskamp, Transition Metals for Organic Synthesis, vol. 2, second ed., Wiley-VCH, Weinheim, 2004, pp. 427-436.

[3] A. Corma, H. Garcia, Chem. Rev. 103 (2003) 4307.

[4] Z.L. Lu, E. Lindner, H.A. Mayer, Chem. Rev. 102 (2002) 3543.

[5] A.P. Wight, M.E. Davis, Chem. Rev. 102 (2002) 3589.

[6] J.H. Clark, D.J. Macquarrie, Chem. Commun. (1998) 853.

[7] Y. Liu, K. Murata, M. Inaba, Green Chem. 6 (2004) 510.

[8] B. Karimi, M. Ghoreishi-Nezhad, J.H. Clark, Org. Lett. 7 (2005) 625.

[9] K. Yamaguchi, C. Yoshida, S. Uchida, N. Mizuno, J. Am. Chem. Soc. 127 (2005) 530.

[10] D.H. Koo, M. Kim, S. Chang, Org. Lett. 7 (2005) 5015.

[11] R.H. Jin, H.X. Li, J.F. Deng, J. Catal. 203 (2001) 75.

[12] H. Chen, W.L. Dai, J.F. Deng, K.N. Fan, Catal. Lett. 81 (2002) 131.

[13] W.L. Dai, H. Chen, Y. Cao, H.X. Li, S.H. Xie, K.N. Fan, Chem. Commun. (2003) 892.

[14] X.-L. Yang, W.-L. Dai, H. Chen, J.-H. Xu, Y. Cao, H. Li, K. Fan, Appl. Catal. A: Gen. 283 (2005) 1.

[15] J. Pyun, K. Matyjaszewski, Chem. Rev. 101 (2001) 2921.

[16] C.Y. Liu, D.Y. Chen, M.C. Cheng, S.-M. Peng, S.-T. Liu, Organometallics 14 (1995) 1983.

[17] D.Y. Zhao, J.L. Feng, Q.S. Huo, N. Melosh, G.H. Fredrickson, B.F. Chmelka, G.D. Stucky, Science 279 (1998) 548.

[18] Y. Liu, K. Murata, M. Inaba, H. Nakajima, M. Koya, K. Tomokuni, Chem. Lett. 33 (2004) 200. 